\title{
COMPARATIVE STUDY OF BMI AND CARDIOVASCULAR FUNCTIONS IN OBESE AND NON OBESE ADOLESCENT MALES
}

\author{
Mahesh Dhotre ${ }^{* 1}$, Gautam Ingale ${ }^{2}$, Ramesh Babu $\mathrm{M}^{3}$.
}

${ }^{{ }_{1}}$ Assistant Professor, Department Of General Surgery, Sambhram Institute Of Medical Sciences, Kolar, Karnataka, India.

${ }^{2}$ Assistant Professor, Department Of General Surgery, Bharathi Vidhyapeeth Medical College, Sangli, Maharashtra, India.

${ }^{3}$ Tutor,Department of Biochemistry, Sambhram Institute Of Medical Sciences, Kolar,Karnataka, , India.

\section{ABSTRACT}

Background: A variety of adaptations/alterations in cardiac structure and function occur in the individual as adipose tissue accumulates in excess amount. As a whole, overweight/obesity predispose or is associated with numerous cardiac complications such as coronary heart disease, heart failure, and sudden death through its impact on the cardiovascular system. This study was undertaken to highlight the effect of electrocardiographic changes $\&$ heart rate variability in obese and non obese on medical students.

MATERIALS AND METHODS: The study included 100 healthy students, 50 obese and 50 normal individuals in the age group of 18-22. ECG was recorded in those students at rest in supine position.

Results: There was an increase in heart rate, P wave, PR interval, QT and decrease in QRS complex, QT interval among obese individuals which were statistically significant.

Conclusion: Remedial measures, policy programs can be formulated as a part of intervention towards the obesity prevention leading to sudden death because of cardiac arrest. Early intervention should be in the form of life style modification and fitness education is provided as a part of their course curriculum.

KEY WORDS: Electro cardiogram (ECG), Medical graduates, Heart rate variability.

Address for correspondence: Dr. Mahesh Dhotre, Assistant Professor, Department Of General Surgery, Sambhram Institute Of Medical Sciences, Kolar, Karnataka, India.

E-Mail:dhotre4u@gmail.com

\begin{tabular}{|c|c|c|}
\hline \multicolumn{3}{|c|}{ Online Access and Article Informtaion } \\
\hline \multirow{2}{*}{ Quick Response code } & \multicolumn{2}{|c|}{$\begin{array}{l}\text { International Journal of Integrative Medical Sciences } \\
\text { ISSN (P): } 2394 \text { - 6318. ISSN (E): } 2394 \text { - } 4137 \\
\text { www.imedsciences.com }\end{array}$} \\
\hline & $\begin{array}{l}\text { Received: 13-06-2018 } \\
\text { Reviewed: 13-06-2018 }\end{array}$ & $\begin{array}{l}\text { Accepted: 25-06-2018 } \\
\text { Published: 05-07-2018 }\end{array}$ \\
\hline Source of Funding: Self & \multicolumn{2}{|c|}{ Conflicts of interest: None } \\
\hline
\end{tabular}

\section{BACKGROUND}

Abnormal or excessive fat accumulation in adipose tissue, to the extent health may be impaired is defined as obesity. It has become more commonly increased. It has become one of the leading global public health problem and underlying causes of non communicable chronic diseases [1]. It has become one of the leading causes of morbidity and mortality in both developed and developing countries [2].
Overweight and obesity has become a worldwide health concern [3]. Prevalence of obesity has increased tremendously in Indians subsequent to the wave of industrialization and modernization [4]. The prevalence of adult overweight and obesity is estimated to rapidly increase worldwide from 937 and 396 million in 2005 to 1.35 billion and 573 million in 2030 . Obesity in adult is defined as having a body mass index that is greater than or equal to 
$30 \mathrm{~kg} / \mathrm{m}^{1,5}$. The normal range of $\mathrm{BMI}$ is between 18.5 and $24.99 \mathrm{~kg} / \mathrm{m}^{2}$ [5]. BMI (Body mass index) is an attempt to quantify the amount of tissue mass in an individual. According to WHO Classification WHO BMI cut-off points for definition $(\mathrm{kg} / \mathrm{m} 2)$ Underweight $<18.5$, Normal range 18.5-24.9, Overweight $\&$ obesity $>=25.0$ [6]. The environmental factors such as lifestyle preferences and cultural practices playing pivotal roles in the rising prevalence of obesity, India has now become the third most common country in the world as per the study conducted by Lancet [7].

Studies have shown that overweight and obesity represents an important risk factor for potentially life threatening health problems associated with medical disorders like hypertension, diabetes,cardiovascular strokes, osteo arthritis, certain cancers, pre mature mortality and respiratory diseases $[8,9]$. It is associated with additional health conditions including carpal tunnel syndrome, deep vein thrombosis and poor wound healing [10]. Obesity is a serious health condition which can cause increase in stroke volume, cardiac output, left ventricular end-systolic pressure and pulmonary artery pressure. The hypervolemic and hyperdynamic status increase left ventricular work and lead to an increase in cardiac mass that is proportional to degree of obesity and increased cardiac mass is due to increased muscle mass of left ventricle and not due to epicardial or myocardial fat infiltration [8].

Obesity is associated with a wide variety of Electrocardiographic (ECG) abnormalities. Most of these abnormalities reflect alterations in cardiac morphology or conduction defects. Some of the ECG parameters act as 'warning signals' for impending 'cardiac catastrophes' and as markers of risk for sudden death. The ECG abnormalities seen in obesity are shift of P-wave, lengthened wave durations, axis deviations and low voltage complexes $[11,12]$. ECG is commonly used to study cardiovascular disorders. It is recorded When the cardiac impulse passes through the heart, electrical current also spreads from the heart into the adjacent tissues surrounding the heart. A small portion of the current spreads all the way to the surface of the body. If electrodes are placed on the skin on opposite sides of the heart, electrical potentials generated by the current. Normal ECG is composed of a $\mathrm{P}$ wave, QRS complex, $\mathrm{T}$ wave, $P R$ and QT interval. The QRS complex is often but not always, three separate waves: $Q, R$ and $S$ wave. Any alterations in this waves leads to arrhythmia [13].

Morbid obesity produces a variety of ECG alterations, including leftward shifts of the P-wave, QRS, and T-wave axis; disproportionately high frequencies of low QRS voltage; left ventricular hypertrophy and left atrial abnormality; and a high frequency of T-wave flattening in the inferior and lateral leads [14]. ECG abnormalities are associated with an increased risk of adverse cardiovascular outcomes, including high resting heart rate (HR), prolonged $P R$ interval, QRS duration and QT interval and abnormal shift in electrocardiographic axes [15].

\section{Objectives:}

1. To analyze the electrocardiogram in individuals.

2. To compare the ECG in obese and normal individuals.

Lacunae of the study: Obesity has become a leading global health problem causing noncommunicable chronic diseases. It is a potential cause of future health related problems including metabolic diseases. Obesity has become more common in India, it has increased more in the medical students because of time-pressures, workload, multiple roles and emotional issues [16]. The outcome of the study will provide the basis for enhancing the general adoption of a new, positive approach to student life, so that early intervention in the form of life style modification and fitness education is provided as a part of their course curriculum.

\section{MATERIALS AND METHODS}

The present study was carried out in medical students at Sambhram institute of medical sciences. A total of 100 subjects - 50 in each of the two BMI categories i.e., obese, and non obese were selected by stratified random sampling technique after applying the inclusion and exclusion criteria. Subjects were categorized into the 2 groups based on the BMI classification for the world's population [11]. This study 
was approved by the Institutional ethics committee. Informed consent \& detailed history were obtained from all the study subjects. The selected subjects were explained about the purpose of study. They were also assured that the information and the results of the tests shared will be confidential and will not be passed to any agency or their employer.

Sample Size: Was estimated by Milovancev et al [3] using the QTC interval in after and before weight loss obese individuals with $90 \%$ Confidence interval and $90 \%$ power sample size of 44 was obtained in each group. With $10 \%$ non response sample size of $44+6 \approx 50$ subjects were included in each group.

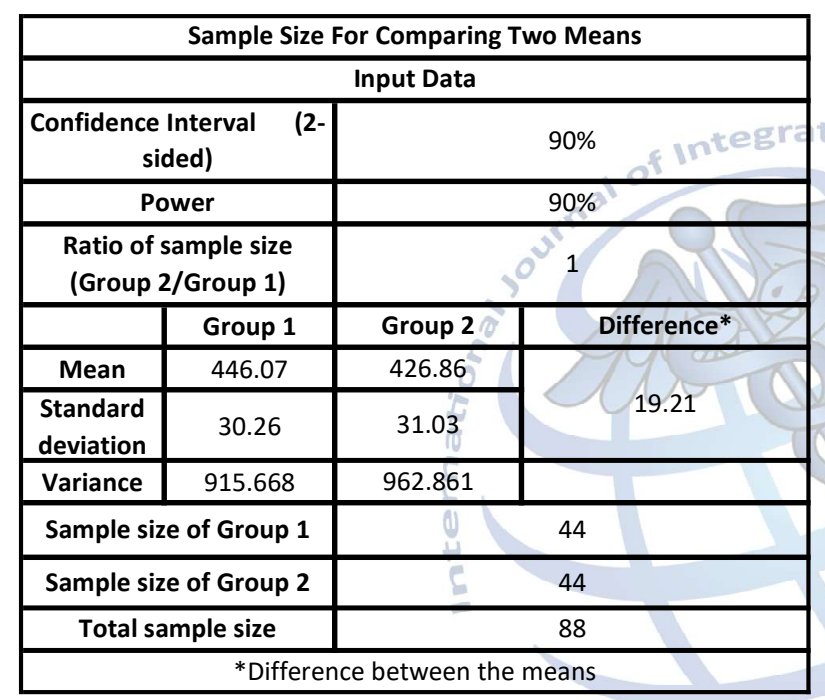

Results from Open Epi, Version 3, open source calculator-SSMean Print from the browser with ctrl-P or select text to copy and paste to other programs.

BMI: Weight was measured with the patient wearing indoor clothing and height was measured without shoes. BMI was calculated by dividing the patient's weight (in $\mathrm{kg}$ ) by the square of the height (in $\mathrm{m}$ ). In accordance with the World Health Organization classification of BMI the subjects were classified into two groups: normal weight $\left(18.5-24.9 \mathrm{~kg} / \mathrm{m}^{2}\right)$ and obese $\left(\geq 30 \mathrm{~kg} / \mathrm{m}^{2}\right)$.

Method ECG is simple, non-invasive test that measures electrical activity of heart. During the test the subject was asked to lie on table in supine position. Electrodes with gel were attached to chest, arms and legs. These electrodes were attached to electrical leads (wires), which will be attached to the ECG machine. The machine will record the electrical activity of heart. After the procedure the electrodes were removed. The following parameters were recorded. P Wave, PR Interval, QRS Complex, ST Segment, T Wave and QT Interval.

Inclusion criteria: Selection of subjects: $18-22$ years Male medical students, having an apparently normal general health and volunteering for the study by giving a written consent.

Exclusion criteria: Documented evidence of heart diseases like Cardiac failure, Cardiomyopathy, Valvular heart disease, Congenital Heart Disease, Myocarditis, Hypertension, arrhythmias. Chronic obstructive pulmonary disease. Alcoholics and Smokers. Chronic medication, Psychiatric illness. Features of hypothyroidism, anemia. BMI $<18 \mathrm{~kg} / \mathrm{m}^{2}$

Analysis and Statistical Methods: Data was coded and entered into Microsoft excel data sheet. Quantitative data will be represented as mean, confidence interval and standard deviation. Paired t test statistical analysis was carried out by using SPSS software. P value $\leq 0.05$ will be considered as statistically significant.

\section{RESULTS}

In this study a total of 100 male subjects were evaluated. Out of that 50 were normals and 50 were obese. The ECG findings were observed and tabulated. Mean age of the study population was $18.27 \pm 1.28$.

Table 1: Showing the Blood pressure, and BMI in obese and normal individuals and its compression.

\begin{tabular}{|c|c|c|c|c|c|}
\hline & \multicolumn{2}{|c|}{ Obese } & \multicolumn{2}{c|}{ Normal } & \multirow{2}{*}{ p-VALUE } \\
\cline { 2 - 5 } & MEAN & SD & MEAN & SD & \\
\hline SBP $\mathbf{m m}$ of $\mathrm{Hg}$ & 125.64 & 5.98 & 111.28 & 7.67 & $0.00^{*}$ \\
\hline DBP $\mathrm{mm}$ of $\mathrm{Hg}$ & 71.28 & 8.01 & 70.51 & 6.86 & 0.65 \\
\hline BMI & 32.17 & 3.43 & 20.98 & 2.32 & $0.00^{*}$ \\
\hline
\end{tabular}

*0.05 statistically significant.,

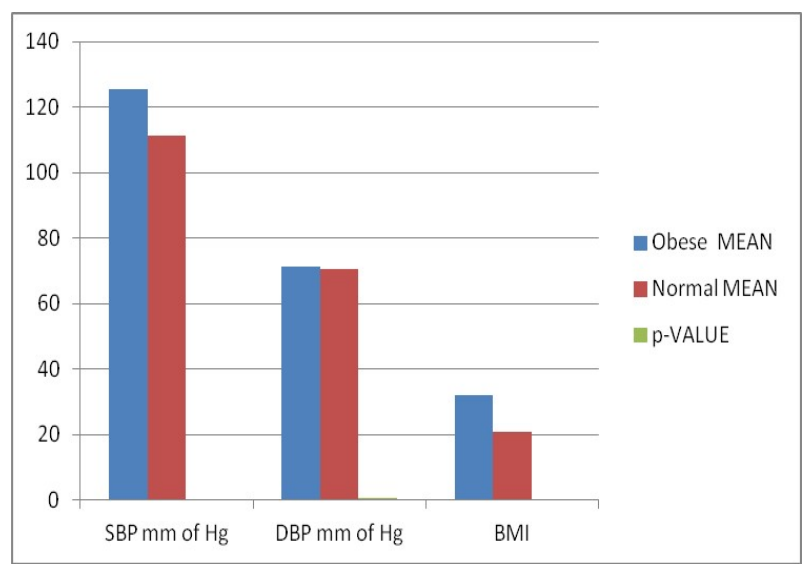


Table 2: Showing the Heart rate, ECG changes in obese and normal individuals and its compression.

\begin{tabular}{|c|c|c|c|c|c|}
\hline & \multicolumn{2}{|c|}{ Obese } & \multicolumn{2}{c|}{ Normal } & \multirow{2}{*}{ p-VALUE } \\
\cline { 2 - 5 } & MEAN & SD & MEAN & SD & \\
\hline $\begin{array}{c}\text { Heart rate } \\
\text { (beats/min) }\end{array}$ & 92.18 & 11.65 & 77.72 & 12.74 & $0.00^{*}$ \\
\hline $\begin{array}{c}\text { P-Duration } \\
\text { (ms) }\end{array}$ & 103.03 & 13.42 & 89.87 & 9.61 & $0.00^{*}$ \\
\hline $\begin{array}{c}\text { PR Interval } \\
\text { (ms) }\end{array}$ & 153.08 & 21.16 & 136.28 & 18.89 & $0.00^{*}$ \\
\hline $\begin{array}{c}\text { QRS Complex } \\
\text { (ms) }\end{array}$ & 84.97 & 6.72 & 88.03 & 6.42 & $0.04^{*}$ \\
\hline $\begin{array}{c}\text { QT-Interval } \\
\text { (ms) }\end{array}$ & 337.49 & 15.34 & 356.62 & 22.82 & $0.00^{*}$ \\
\hline QTC & 419.26 & 7.57 & 404.38 & 20.14 & $0.00^{*}$ \\
\hline
\end{tabular}

*0.05 statistically significant

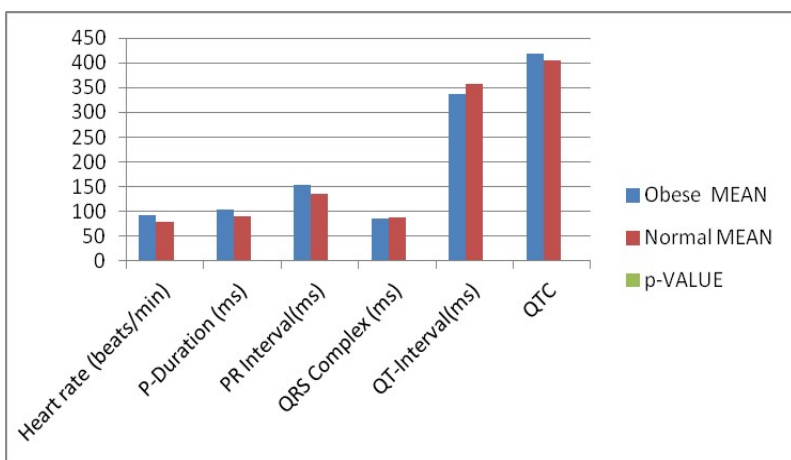

Table 1 showing the BMI, Systolic blood pressure (SBP) and diastolic blood pressure (DBP) of the study population. There was a statistically significant increase in BMI and SBP in obese when compared to normal individuals. There was a slightly increased in DBP among obese which was statistically not significant.

Table 2 showing the Heart rate, P duration, PR interval and $Q T_{C}$ were increased and decreased QT interval and QRS complex were seen among obese respectively and all of them mentioned above were statistically significant.

\section{DISCUSSION}

Studies have shown that overweight and obesity represents an important risk factor for potentially life threatening health problems associated with medical disorders like hypertension, diabetes, cardiovascular strokes, osteo arthritis,certain cancers, pre mature mortality and respiratory diseases [8,9]. Obesity is a serious health condition which can cause increase in stroke volume, cardiac output, left ventricular end-systolic pressure and pulmonary artery pressure which can lead to arrhythmia.

According to table 1 there was statistically significant increase in SBP,Studies have shown that weight loss leads to decreased blood pressure in hypertensive individuals. Improper renal sodium balance, water reabsorption and impaired pressure natriuresis appear to play a major role in obesity-related hypertension. In order to maintain the sodium balance, obese individuals shows increased arterial pressure. Some other studies shows the mechanism of obesity-induced hypertension is by activation of the sympathetic nervous system, which was known to alter pressure natriuresis. Activation of sympathetic nervous system might be important in explaining the variations in blood pressure observed in our study. In addition to that there would be elevated glomerular filtration rate and renal plasma flow which was demonstrated in many studies [17].

There was a statistically significant increase in heart rate was seen in obese compared to normals which shows a positive correlation between heart rate and BMI. Similar findings were reported by paradis et al. Some studies have shown that increased heart rate is due to increased in percentage of body fat. A $10 \%$ increase in body weight is associated with a decline in parasympathetic tone accompanied by a rise in mean heart rate and conversely, heart rate declines during weight reduction. This is of importance because higher heart rate is associated with Strokes, cardiac failures and increased mortality rates [18].

There was a statiscally significant increase in $\mathrm{P}$ wave among obese. This wave duration is a marker of atrial conduction. Prolonged $P$ wave duration signifies conduction delay between right \& left atrium due to impulse slowing or blockage has been suggested to be an easily measurable risk factor for underlying subclinical heart disease. In fact, it has been associated with atrial fibrillation (AF), diabetes, cardiovascular disease (CVD) and stroke mortality among population. Similar findings were reported by Vepsalainen et al and Magnani et al $[19,20]$.

There was a statistically significant PR interval in obese individuals when compared to normals. Usually if the heart rate increases there should be decrease in PR interval which is a major determinant of PR interval. The reason for increased PR interval is not yet known and further 
studies are required to find the cause for increased PR interval in obese. Similar findings were reported by bhide et al and Paul Poirier et al $[18,21]$.

In this study, QT interval showed statistically significant decrease in obese individuals when compared to normal individuals. This might be due to left ventricular hypertrophy, left ventricular diastolic dysfunction, increased degree of myocardial repolarization in homogeneity, changes in sympathetic- vagal balance, increase in catecholamine levels, increase in free fatty acid levels which affect repolarization

\section{$[22,18]$.}

There was statistically significant decrease in QRS axis in obese individuals compared to normal which was due to upward shift of diaphragm resulting in more horizontal position of heart and also due to increased cardiac work load in obese [21].

We also found a statiscally significant increase in QTc interval among obese which may be due to autonomically induced repolarization changes by ANS imbalance, adrenergic release, increased sympathetic tone. Similar findings were reported by Paul Poirier and Boban Mathew et al [21,22].

Limitations: The inclusion of different parameters like waist hip ratio and body fat percentage will gives better picture about obesity and its cardiovascular effects.

\section{CONCLUSION}

Obesity is associated with numerous co-morbidities such as cardiovascular diseases (CVD), type 2 diabetes, hypertension, certain cancers, and sleep apnea/sleep-disordered breathing. In fact, is an independent risk factor for CVD and CVD risks have been also documented in obese children, and is associated with reduced life expectancy. A variety of adaptations/alterations in cardiac structure and function occur in the individual as adipose tissue accumulates in excess amount. As a whole, overweight/obesity predispose or is associated with numerous cardiac complications such as coronary heart disease, heart failure, and sudden death through its impact on the cardiovascular system.

The influence of obesity causing the cardiac abnormalities is proved beyond doubt, from the significant ECG changes, especially left ventricular hypertrophy which is an important risk factor for sudden cardiac arrest. So, this noninvasive procedure may be utilized as a routine screening test for obese people for better medical care. In addition, the results necessitate further study to evaluate this medical condition thoroughly as a potential risk factor for cardiac dysfunction. Early diagnosis of obesity and cardiovascular changes will be highly useful to clinicians. Remedial measures, policy programs can be formulated as a part of intervention towards the obesity prevention leading to sudden death because of cardiac arrest. Early intervention should be in the form of life style modification and fitness education is provided as a part of their course curriculum.

\section{ACKNOWLEDGEMENT}

We would like to acknowledge the volunteers who have co-operated for this study for their continuous help, support and encouragement to carry the study.

\section{REFERENCES}

[1]. Konakanchi S, Pagadala P, Babu MR, Gouraj S. Assessment of existence metabolic risk factors in obese males and females. Int J Intg Med Sci 2017; $4(2): 466-70$.

[2]. Omisorea B, Omisoreb A, Abioye Kuteyic E. obesity prevalence and metabolic differences between obese and non-obese school adolescents. Safr Fam Pract 2015; 57(3):172-176

[3]. Milovancev A, Stokic E, Popovic DS, Naglic DT, Rankov O. Body Weight Reduction and QTc Interval in Obesity. Adv Weigh Loss Manag Med Dev 2016; 1(1):102.

[4]. Bakshi AA, Bavikar JS, Asegaonkar S B, Bardapurkar JS, Domple V, Rai SK et al,. Evaluation of Usefulness of Serum Insulin as Sensitive Predictor of Cardiovascular Dysfunction in Obese Individuals with Normal Lipid Profile. J Clin Diagn Res 2014;8:10-12.

[5]. Kalra S, Unnikrishnan AG. Obesity in India: The weight of the nation. J Med Nutr Nutraceut 2012;1:37-41.

[6]. Chandrashekar N, Pagadala P, Nerella S, Babu R. Comparative study of body mass index and pulmonary functions between overweight and normal weight women. Natl J Physiol Pharm Pharmacol 2018;8(8):1-3.

[7]. Karthikkeyan K, Umadevi TB. ECG Changes in Obese Individuals. JMSCR 2016; 4 (11) :14174-7

[8]. National Institutes of Health Clinical guidelines on the identification, evaluation, and treatment of overweight and obesity in adults The evidence report. National Institutes of Health. Obes Res 1998; 6 ( 2):51S-209S 10. 
[9]. Nerella S, Pravallika P, Ahmed N. Relation of obesity with total leucocyte in metabolic syndrome.Indian journal of appled research 2015;5(5):7-9.

[10]. National Institutes of Health Consensus Development Panel on the Health Implications of obesity. Ann Intern Med 1985;103:1073-77.

[11]. Fraley MA, Birchem JA, Senkottaiyan N, Alpert MA. Obesity and the electrocardiogram. Obes Rev 2005;6(4):275-81.

[12]. Narasimha Swamy K N, Kumar A, Sudhir GK. Association between ECG Variables and Body Mass Index: A Cross-sectional Study. Journal of Evolution of Medical and Dental Sciences 2015; 96( 4): 161325.

[13]. Guyton \& Hall. Text book of medical physiology. Jaypee publishers.2017; 191.

[14]. Alpert MA, Terry BE, Hamm CR, Fan TM, Cohen $M V$, Massey CV et al. Effect of weight loss on the ECG of normotensive morbidly obese patients. Chest 2001;119(2):507-10.

[15]. Neil BJ, Hoekstra J, Pride YB. Incremental benefit of 80-lead electrocardiogram body surface mapping over the 12-lead electrocardiogram in the detection of acute coronary syndromes in patients without ST-elevation myocardial infarction: Results from the Optimal Cardiovascular Diagnostic Evaluation Enabling Faster Treatment of Myocardial Infarction trial. Acad Emerg Med 2010;17:932-39.

[16]. Eva EO, Islam MZ, Mosaddek AS, Rahman MF, Rozario RJ, Hassan Iftekhar AF et al. Prevalence of stress among medical students: a comparative study between public and private medical schools in Bangladesh.BMC Res Notes 2015; 8: 327.

[17]. Vasilios K, Stella S, Marshall B, Annette L, Savvas T, Nikos Z. Impact of Obesity on 24-Hour Ambulatory Blood Pressure and Hypertension. Hypertension 2005;45:602-07 DOI: 10.1161/01. HYP.0000158261. $86674.8 \mathrm{e}$
[18]. Bhide A, Begum N, Kasala L, Velam V. Electrocardiographic Changes in Relation to Body Mass Index. International Physiology 2014; 2 (1): 13-20.

[19]. Magnani JW, Gorodeski EZ, Johnson VM, Sullivan LM, Hamburg NM, Benjamin EJ, Ellinor PT. P wave duration is associated with cardiovascular and allcause mortality outcomes: the national health and nutrition examination survey. Heart Rhythm 2011;8:93-100.

[20]. Vepsalainen T, Laakso M, Lehto S, Juutilainen A, Airaksinen J, Ronnemaa T.Prolonged $P$ wave duration predicts stroke mortality among type 2 diabetic patients with prevalent non-major macrovascular disease. BMC Cardiovasc Disord 2014; 14: 168.

[21]. Poirier P. Abdominal obesity: an important risk factor in clinical and interventional cardiology. Official Journal of the International Chair on Cardiometabolic Risk 2008; 2(1): 7-14.

[22]. Mathew B, Francis L, Kayalar A, Cone J. Obesity: effects on cardiovascular disease and its diagnosis. The Journal of the American Board of Family Medicine 2008; 21(6): 562-68.

[23]. Poirier P, Giles TD, Bray GA, Hong Y, Stern JS, PiSunyer FX, Eckel RH. Obesity and cardiovascular disease: patho physiology, evaluation, and effect of weight loss. Arterioscler Thromb Vasc Biol. 2006; 26(5):968-76.

How to cite this article: Mahesh Dhotre, Gautam Ingale, Ramesh Babu M. COMPARATIVE STUDY OF BMI AND CARDIOVASCULAR FUNCTIONS IN OBESE AND NON OBESE ADOLESCENT MALES. Int J Intg Med Sci 2018;5(6):667-672. DOI: 10.16965/ijims.2018.121 